Article

\title{
Operational Temperature Effect on Positioning Accuracy of a Single-Axial Moving Carrier
}

\author{
Kun-Ying Li ${ }^{1,3}$, Win-Jet Luo ${ }^{1, *}$, Jun-Zheng Huang ${ }^{2}$, Yung-Chao Chan ${ }^{3}$, Pratikto ${ }^{4}$ \\ and Dini Faridah ${ }^{2}$ \\ 1 Graduate Institute of Precision Manufacturing, National Chin-Yi University of Technology, Taichung 41170, \\ Taiwan; likunying@itri.org.tw \\ 2 Department of Refrigeration, Air-Conditioning and Energy Engineering, National Chin-Yi University of \\ Technology, Taichung 41170, Taiwan; takashi6120@gmail.com (J.-Z.H.); faridahdini@gmail.com (D.F.) \\ 3 Industrial Technology Research Institute, Intelligent Machinery Technology Center, Taichung 40768, Taiwan; \\ itriA20268@itri.org.tw \\ 4 Department of Refrigeration and Air Conditioning Engineering, Politeknik Negeri Bandung, \\ Bandung 40559, Indonesia; pratikto@hotmail.co.jp \\ * Correspondence: wjluo@ncut.edu.tw; Tel.: +886-423-924-505 (ext. 5110)
}

Academic Editors: Chien-Hung Liu and Huei-Chu Weng

Received: 29 December 2016; Accepted: 17 April 2017; Published: 20 April 2017

\begin{abstract}
This study investigated the ambient environmental temperature effect on the positioning accuracy of a periodically-moving carrier. The moving carrier was operated in an environmental chamber in which the operational temperature could be controlled by an air conditioning system. Different operational temperature modes, including a stable environment, a rise in temperature, a decline in temperature, summer daytime hours, and winter nighttime hours in terms of seasonal climate change in Taiwan, were generated within the environmental chamber by an air conditioning system to investigate the operational temperature's effect on positioning accuracy. From the experimental measurements of a periodically-moving carrier, it is found that the operational temperature conditions can significantly affect the positioning accuracy of the moving carrier, especially in the case of an operational temperature decline. Under stable operational conditions, the positioning accuracy of the moving carrier can be considerably improved. In comparison to the case of an operational temperature decline, the positioning accuracy improvement can reach $29.6 \%$. Moreover, the effect of the temperature distributions within the chamber on the positioning accuracy was further investigated. It was found that, with a parallel flow pattern in the chamber, the positioning accuracy can be further enhanced.
\end{abstract}

Keywords: positioning accuracy; environmental temperature; machine tool; environmental chamber

\section{Introduction}

Demands for high production in the manufacturing industry are increasing due to global competition. The use of machine tools in current industrial development is required to generate higher productivity because of the great demand for products. Production speed, accuracy, and precision are also highly necessary as a form of product quality. The reliability of machine tools is one of the more important aspects that researchers have investigated [1-5]; however, the correlation between their reliability and environmental temperature has not been studied in depth. Whether it is the machine tools themselves or the outside environment, it is possible to impose direct or indirect impacts on processing accuracy. There is one problem in particular, namely, thermal deformation during processing, which has been receiving increasing attention in recent years [6-8]. 
In the past, most literature has engaged in investigations on thermal compensation to reduce thermal deformation from heat sources in machines. For a high rotating speed spindle $(20,000 \mathrm{rpm})$, the largest thermal deformation can attain $180 \mu \mathrm{m}$. It was found that the displacement-based thermal error model has much better accuracy and robustness than the temperature-based model [9]. Sun-Kyu et al. [10] described the effects on machine slide-guide contact conditions caused by thermal deformation. The thermal deformation of the table and the guide generated not only a change of motion that was straighter, but also pitching and yawing motion changes. The thermal distortion of the slide table caused a decrease in friction force of over $30 \%$ due to the non-uniformity of the slide contact between the table and the guide surface. Xia et al. [11] investigated the influence of the runtime on positioning accuracy and thermal deformation of a high-speed feed system experimental bench. The thermal deformation caused by a rise in temperature is much greater than the geometric error of the feed system itself. As the runtimes of a feed system increase, the axial thermal deformations become larger, but after running for a period of time, the feed system approaches a thermal balance and reaches the approximate steady state, and the variations in thermal deformation ease up. In the literature [9-11], thermal deformations caused by frictional heat, heat of bearing contact, cutting force, and feeding speed have been investigated. The impact of environmental temperature variations on the positioning accuracy of machines was not considered. Mian et al. [12] presented a novel offline thermal error modeling methodology using finite element analysis (FEA), which significantly determined the minimum experimental testing time required for a machine. A sample of the data shows that the FEA-based method correlated well with the experimental results, resulting in residual errors of less than $12 \mu \mathrm{m}$. Tan et al. [13] united two models to create a synthetic thermal error prediction model called the environmental temperature consideration prediction (ETCP) model. The proposed model shows high robustness and universality, with a thermal error over $85 \%$ and precision predicted by up to $0.2 \mathrm{~mm}$.

As the main equipment for advanced manufacturing technology, machine tools have been applied widely in many industries and regions. The types of machining workpieces also vary dramatically from user to user. Atmospheric pressure and temperature differ substantially from one region to another, and, therefore, machine tools are usually employed under many different working conditions [14]. During the processing of a machine tool, the environmental temperature of the processing area greatly influences the accuracy of the products. This raises the concern of effectively controlling the environmental temperature in the processing area while isolating pollution and interference from the outside environment. Toshimichi et al. $[15,16]$ studied thermal deformation inside the machine with the variation in environmental temperature. It was found that the thermal deformation brought on by environmental temperature variations increased with the increase in the rotating speed of the spindle. Therefore, environmental temperature control is required to improve the precision of rotating spindles as well. Fletcher et al. [17] monitored the spindle movement over days rather than hours to measure daily cyclic environmental temperature fluctuations and associated errors. They provided information about cyclic environmental fluctuations and drifts with a 50\% reduction in errors over a $65 \mathrm{~h}$ test and drew attention to the detrimental amount of machine downtime for thermal characterization tests. However, the daily environmental temperature variations in different seasons in one year may totally differ, especially in summer and winter. The effect of daily temperature variations in terms of different seasons has not been investigated well in the literature. Environmental temperature variations can affect the energy consumption of a machine tool as well. Diaz et al. [18] also argued that a location with a different temperature was found to have a significant influence on environmental impacts, resulting in changes in the annual energy consumption relative to the baseline that ranged from $-10 \%$ to $8 \%$. Diaz et al. [19] analyzed the lifetime energy consumption of a machine tool, including transportation, material inputs, and facility input. The results of their analysis provide greater value than previous work because they highlighted the areas with the greatest opportunity for energy optimization. The results also indicate that environmental impacts consume a large portion of the lifetime energy consumption. 
In terms of the studies on environmental temperature control, Jin and Shi [20] noted how changes in the locations of air openings can affect air velocity and air distribution in an experimental area. $\mathrm{Li}$ et al. [21] probed into the temperature homogeneity control of greenhouses via computational fluid dynamics (CFD) and proposed a factor-optimized control based on the design of experiments concerning a CFD simulation model. Thus, they acquired the best combination of environmental control factors through a relatively small number of computational simulations and analyses. Chang [22] used numerical analyses and CFD software to simulate the air flow organization at a constant temperature in a humidity chamber. A mathematical model of the temperature control chamber was established in the experiments based on system identification theories. Applications of proportional-integral-derivative (PID) control theories in temperature control chambers have also been investigated. In the past, the effect of flow patterns in an environmental control chamber on manufacturing precision has also not been investigated.

For high-precision machine tools, the requirement of current positioning accuracy is less than $10 \mu \mathrm{m}$ in industry. In terms of environmental conditions, environmental temperature variations for high-precision machines in industry are usually required to be in the range of -0.5 to $0.5^{\circ} \mathrm{C}$. In the past, most literature has investigated thermal compensation to reduce thermal deformation from the heat sources in the machines. Thermal deformation of the structure coming from the ambient temperature variations needs to be investigated further.

The main purpose of thermal compensation is to reduce thermal deformation caused by heat sources, for example, the spindle. However, thermal deformation of a structure coming from the ambient temperature variations cannot be compensated for by existing thermal compensation designs. In the past, thermal deformation resulting from daily ambient temperature variations, in terms of different seasons and the effect of flow patterns around the moving machines on positioning accuracy, has not been experimentally investigated. That is the reason why this paper investigates the ambient temperature's effect on the positioning accuracy of a moving carrier. In this study, a moving carrier operates in an environmental chamber in which the operational temperature can be controlled by an air conditioning system. Different operational temperature modes, including a stable environment, temperature rise, temperature drop, summer daytime hours, and winter nighttime hours, were generated within the environmental chamber by the air conditioning system to investigate the operational temperature's effect on positioning accuracy. In addition, analyses were based on CFD simulations, aiming to investigate the locations of air inlets and air outlets on the flow field in the chamber to ensure the stability of air flow and the laminar field within the processing area, hence, achieving further improvements in terms of the positioning accuracy of a moving carrier.

\section{Mathematical Theoretical Models and Experimental Methods}

\subsection{Structure of the Moving Carrier}

A periodically-moving carrier was used in this study, with an overall size of $1200 \mathrm{~mm}$ (length) $\times 580 \mathrm{~mm}$ (width) $\times 540 \mathrm{~mm}$ (height). The size of the moving carrier in the study was $500 \mathrm{~mm}$ (length) $\times 500 \mathrm{~mm}$ (width) $\times 110 \mathrm{~mm}$ (height), while the linear motor used in processing had a width of $195 \mathrm{~mm}$ and a height of $56 \mathrm{~mm}$, as shown in Figure 1. A linear motor (GENTEC LC50100W2AD\&LS50216C, Shun-Peng Technology Co., Ltd, Taichung, Taiwan) was employed to drive the carrier, periodically moving along linear guideways.

To maintain stable environmental temperature distribution in the processing area, an environmental control system was designed to supply the area with air at a constant temperature. The environmental chamber had a width of $1600 \mathrm{~mm}$, a length of $2600 \mathrm{~mm}$, and a height of $1100 \mathrm{~mm}$. The size of the air inlet and outlet of the designed environmental system was $800 \mathrm{~mm} \times 150 \mathrm{~mm}$. Figure 2 shows the relative position of the air inlets and outlets in the environmental chamber and the experimental setup in the study. 


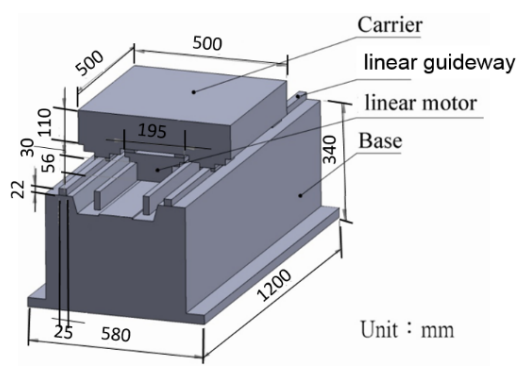

Figure 1. Structural drawing of the moving carrier.

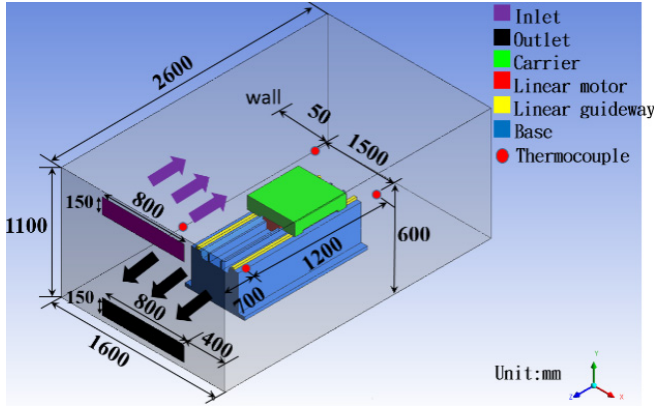

(a)

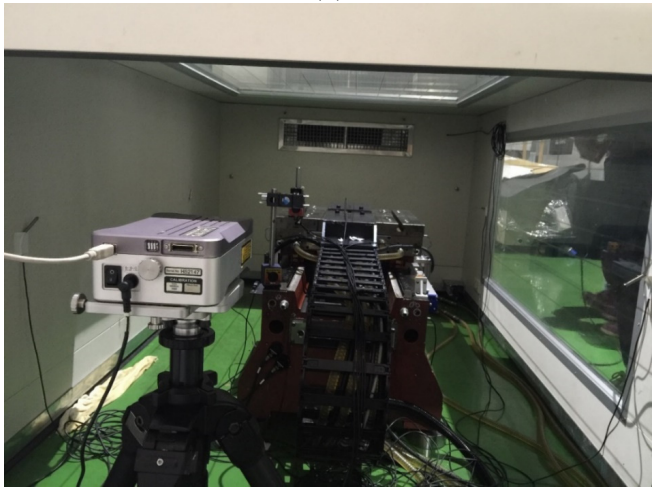

(c)

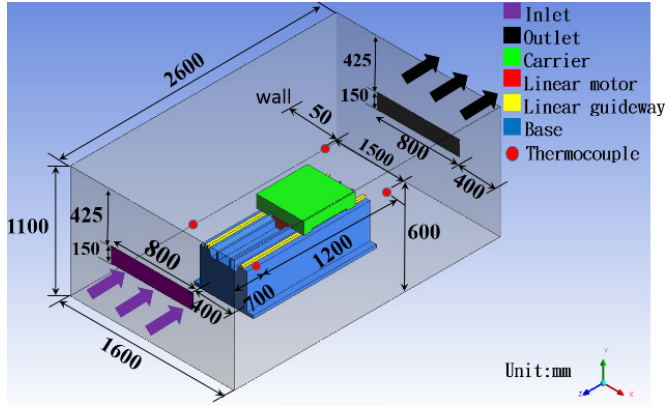

(b)

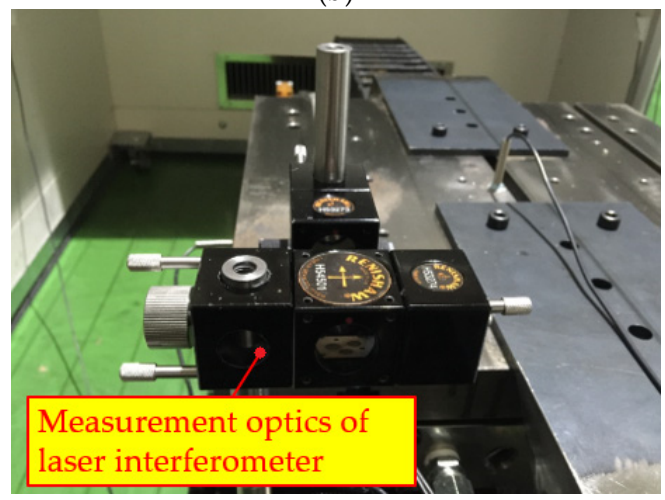

(d)

Figure 2. The relative position of the air inlet and outlet in the environmental chamber during the numerical study and the experimental setup: (a) the air inlet and outlet are located on the same side of the chamber; (b) the air inlet and outlet are located on opposite sides of the walls; (c) image of the experimental setup; (d) Renishaw laser interferometer. The red circles in figures $(\mathbf{a}, \mathbf{b})$ represent the corresponding locations of the thermocouples in the experimental study.

Four thermocouple temperature detection components were laid outside the moving machine and near the heat source during the practical component processing to measure environmental temperature distribution in the process. Via this measurement, the heat power generated by the main heat sources could be estimated. In the study, the size of the environmental chamber is quite small and the flow field in the chamber is a laminar flow. The measured temperature deviations among the four thermocouples are less than $0.2{ }^{\circ} \mathrm{C}$, and only the environmental temperature distributions around the moving carrier are our main concerns. Thus, four thermocouples were employed to measure the environmental temperatures around the moving carrier, as shown in Figure 2, and Figure 3 shows a schematic diagram of the environmental control system in the study. The temperature in the environmental chamber can be controlled by an air conditioning system. The returning air from the environmental chamber can be cooled down after passing through the evaporator, then the temperature of the process air can be compensated by a heater which is controlled by a PID controller in terms of the temperature measured by a thermocouple (PT100), as shown in Figure 3. 


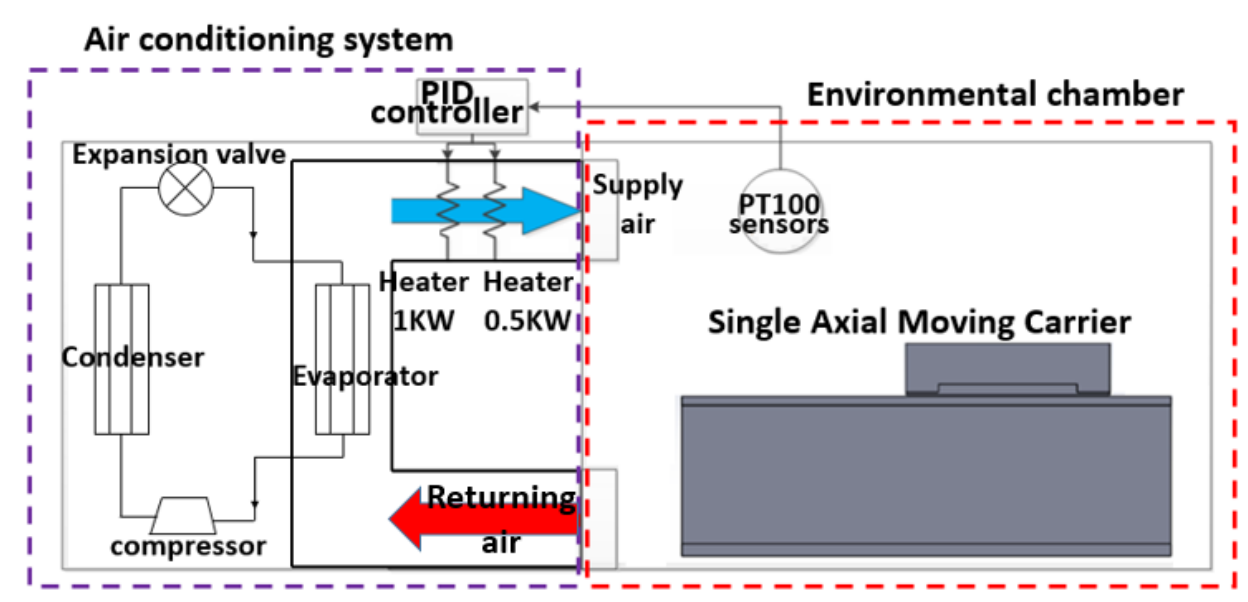

Figure 3. Schematic diagram of environmental control system in the study.

In order to control the temperature in the chamber, while the temperature measured by the thermocouple is less than the setting value, the process air is heated by the heater in terms of the feedback signals from the thermocouple.

\subsection{Positioning Accuracy Measurement of the Moving Carrier}

The precision of a measurement system, also called reproducibility or repeatability, is the degree to which repeated measurements under unchanged conditions show the same results. In the fields of science, engineering, industry, and statistics, the accuracy of a measurement system is the degree of closeness in measurements of a quantity to that quantity's actual value [23].

The positioning accuracy of the moving carrier was measured by a laser optic measurement system composed of an XL-80 (laser measurement equipment from the Renishaw company, Gloucestershire, $\mathrm{UK})$, a laser generator, an optic lens module, temperature sensors, and a temperature compensating component XC-80, as shown in Figure 4 [24]. This experiment set the Renishaw laser interferometer on a single-axis stage. The laser beam was aligned with the direction of the axial movement, and an adjustment was performed for the linear positioning lens group with the principle of adjusting the proximal end and the angle. The results of the analysis are in accordance with the VDI3441, which is the standard to measure positioning precision and repeat accuracy. This method uses software that can measure the reversal error average, positional scatter average, maximum reverse error, positioning accuracy, maximum repeat accuracy, and position deviation.

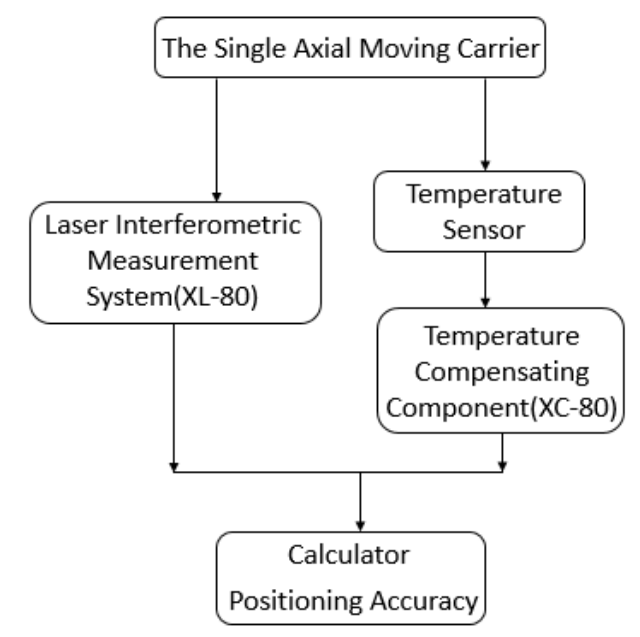

Figure 4. Schematic diagram of a laser optic measurement system [24]. 
The equipment properties used in the experiment are presented as follows:

1. PT100 temperature sensor

The temperature sensors used in this paper are in line with the international IEC 751 standard for temperature sensors, with the temperature ranging from -200 to $+850{ }^{\circ} \mathrm{C}$, having a resistance of $100 \mathrm{ohms}$ at $0{ }^{\circ} \mathrm{C}$ and $138.4 \mathrm{ohms}$ at $100^{\circ} \mathrm{C}$. The measured temperature data were collected by a data $\log$ (GRAPHTEC GL-840-M) with an interval of $5 \mathrm{~s}$.

2. Laser measurement system

- Laser frequency stability of $\pm 0.05 \mathrm{ppm}$ over one year and $\pm 0.02 \mathrm{ppm}$ over $1 \mathrm{~h}$ is achieved by dynamic thermal control of the laser tube length to within a few nanometers.

- Linear measurement accuracy of $\pm 0.5 \mathrm{ppm}$ is achieved over the whole environmental range, i.e., from $0-40{ }^{\circ} \mathrm{C}\left(32-104{ }^{\circ} \mathrm{F}\right)$ and $650-1150$ mbar. Readings can be taken up to $50 \mathrm{kHz}$, with a maximum linear measurement speed of $4 \mathrm{~m} / \mathrm{s}$ and a linear resolution of $1 \mathrm{~nm}$, even at maximum speed.

3. The air velocity at the inlet vent was measured by a flow meter (Fluke 923) with an accuracy of $\pm 2.5 \%$.

\section{Results and Discussions}

\subsection{Positioning Accuracies under Different Operational Temperature Conditions}

In our experiments, the moving speed and movement stroke of the single axial carrier are $8.5 \mathrm{~mm} / \mathrm{s}$ and $400 \mathrm{~mm}$, respectively. An air velocity of $1.18 \mathrm{~m} / \mathrm{s}$ was employed. The air inlet and outlet were located on the same side of the chamber. During the measurements, one stroke of $400 \mathrm{~mm}$ was divided into six individual measuring points. The distance between each point was $80 \mathrm{~mm}$, and the positioning accuracy of the carrier can be obtained by averaging the measured positioning accuracies of the six points. Different environmental temperatures can be created within the designed environmental chamber to investigate the ambient temperature effect on the positioning accuracy of the moving carrier. Figure 5 illustrates the distribution of the temperature rise and drop within the chamber over a period of $150 \mathrm{~min}$, respectively, in which the brown line indicates the temperature distribution in the chamber without an environmental control. In Taiwan, the lowest indoor temperature in wintertime is about $15{ }^{\circ} \mathrm{C}$, and the highest indoor temperature in summertime is about $33{ }^{\circ} \mathrm{C}$. Thus, the two temperatures are chosen to be the limit values in the cases of temperature rise and temperature decline. In this case, the initial temperature was maintained at approximately $23{ }^{\circ} \mathrm{C}$ while the carrier was halted. When the time reached $30 \mathrm{~min}$, the carrier started to move, and heat was generated from the driving linear motor and the frictional force between the carrier and the linear guideway. Thus, the temperature inside the chamber gradually increased with time and attained a value of $27^{\circ} \mathrm{C}$ after $60 \mathrm{~min}$. The dotted line indicates the temperature distribution in the case in which the environmental temperature was controlled to approach a value of $23^{\circ} \mathrm{C}$ with a $0.5^{\circ} \mathrm{C}$ variation, while the carrier periodically moved at a speed of $400 \mathrm{~mm} / \mathrm{s}$. An ambient temperature setting of $23^{\circ} \mathrm{C}$ was used in a stable ambient operational condition considering the thermal expansion characteristics of the materials. In addition, the average moving speed of the carrier in real applications of machines is about $400 \mathrm{~mm} / \mathrm{s}$. To investigate the effect of a rising ambient temperature on the positioning accuracy of the moving carrier, an air conditioning system was applied to create the operational conditions of the rising temperature, as shown by the yellow dotted line in Figure 5. As the time elapsed to $70 \mathrm{~min}$, the operational temperature attained a value of $33^{\circ} \mathrm{C}$ and then was controlled at approximately $32{ }^{\circ} \mathrm{C}$ with a variation of $0.5^{\circ} \mathrm{C}$. Similarly, an air conditioning system was designed to create a temperature decline in the ambient operational conditions for the moving machine to investigate the effect of an ambient temperature drop on the positioning accuracy of the moving carrier, as shown by the deep 
green dotted line in Figure 5. The operational temperature declined from 23 to $14.5^{\circ} \mathrm{C}$ in $66 \mathrm{~min}$ and then, was controlled at about $15^{\circ} \mathrm{C}$ with a variation of $0.5^{\circ} \mathrm{C}$.
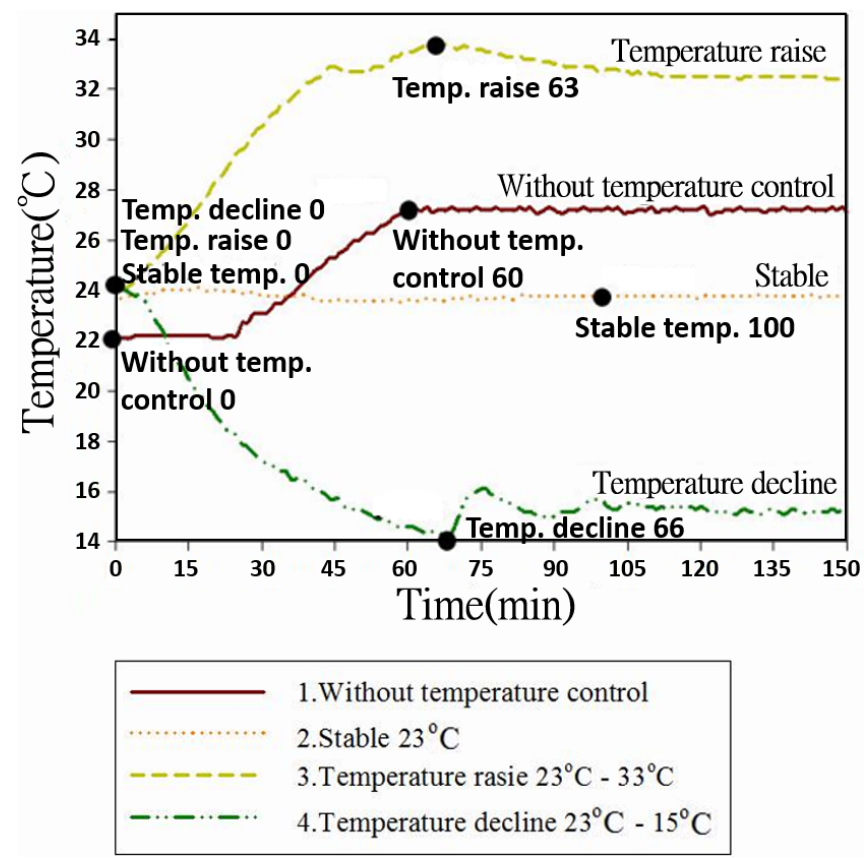

Figure 5. Temperature distributions within the environmental chamber with stable environment, temperature raise, and temperature decline modes.

Table 1 indicates the corresponding positioning accuracy of the periodically-moving carrier under different operational temperature conditions. As shown in the table, the positioning accuracy of the moving carrier is approximately $18.3 \mu \mathrm{m}$ in the case without an ambient temperature control, initially at time $=0 \mathrm{~min}$ (without temp. control 0). However, when the carrier started to move, the operational temperature gradually increased with time. At the time of $60 \mathrm{~min}$ (without temp. control 60), the operational temperature rose to $27.8^{\circ} \mathrm{C}$, and the corresponding positioning accuracy was improved to $17.37 \mu \mathrm{m}$. Thus, during the period of $60 \mathrm{~min}(t=0 \mathrm{~min}$ to $t=60 \mathrm{~min}$ ), the positioning accuracy variation was $-0.93 \mu \mathrm{m}$, and the positioning accuracy variation rate, in terms of time and operational temperature difference, was $-0.00304 \mu \mathrm{m} /\left(\mathrm{min} \cdot{ }^{\circ} \mathrm{C}\right)$. Compared to the case in which the operational temperature was controlled at a value of $23^{\circ} \mathrm{C}$ with a $0.5^{\circ} \mathrm{C}$ variation, the positioning accuracy improved from 17.96 to $16.14 \mu \mathrm{m}$, the positioning accuracy variation was $-1.82 \mu \mathrm{m}$, and the positioning accuracy variation rate was $-0.0182 \mu \mathrm{m} /\left(\mathrm{min} \cdot{ }^{\circ} \mathrm{C}\right)$ over a period of $100 \mathrm{~min}$ from stable temp. 0 to stable temp. 100. In the case with a stable operational temperature, the positioning accuracy attained an improvement of $2.16 \mu \mathrm{m}(18.3-16.14 \mu \mathrm{m})$ in comparison to the prior case. For the case with a stable operational temperature, the accuracy variation and accuracy variation rate were greatly improved over those in the case without a temperature control. This implies that, in the case with a stable operational temperature, the positioning accuracy gradually improved with time and temperature variation.

Table 1 also indicates the corresponding positioning accuracy of the periodically-moving carrier under operational conditions for both temperature rise and decline. The table shows that in the case with an operational temperature rise, the initial operational temperature was $23.8^{\circ} \mathrm{C}$ and the corresponding positioning accuracy was $16.14 \mu \mathrm{m}$. The operational temperature then gradually increased to attain a value of $33.3{ }^{\circ} \mathrm{C}$ at $t=63 \mathrm{~min}$, at which time the corresponding positioning accuracy reached $20.69 \mu \mathrm{m}$. During the period of $63 \mathrm{~min}(t=0 \mathrm{~min}$ to $t=63 \mathrm{~min})$ when the temperature rose, the positioning accuracy variation was $4.55 \mu \mathrm{m}$ and the positioning accuracy variation rate 
was $0.0076 \mu \mathrm{m} /\left(\min \cdot{ }^{\circ} \mathrm{C}\right)$. This phenomenon indicates that with a rise in operational temperature, the positioning accuracy worsens with time and an increase in operational temperature. As indicated in the table, the initial operational temperature was $23.6{ }^{\circ} \mathrm{C}$, and the corresponding positioning accuracy was $14.93 \mu \mathrm{m}$. In the case of an operational temperature decline, the operational temperature gradually declined to attain a value of $15.7^{\circ} \mathrm{C}$ at $t=66 \mathrm{~min}$ at which time the corresponding positioning accuracy reached $22.94 \mu \mathrm{m}$. During the temperature decline period of $66 \mathrm{~min}(t=0 \mathrm{~min}$ to $t=66 \mathrm{~min}$ ), the positioning accuracy variation was $8.01 \mu \mathrm{m}$, and the positioning accuracy variation rate was $0.01536 \mu \mathrm{m} /\left(\mathrm{min} \cdot{ }^{\circ} \mathrm{C}\right)$. From the positioning accuracy variations in the case of an operational temperature decline, it is found that, for the periodically-moving carrier, positioning accuracy can substantially worsen with time and operational temperature decline.

Table 1. Corresponding positioning accuracy of the periodically-moving carrier under stable temperatures, a rise in temperature, and a decline in temperature.

\begin{tabular}{|c|c|c|c|c|c|c|}
\hline No. & Time Point & $\begin{array}{c}\text { Chamber } \\
\text { Temperature } \\
\left({ }^{\circ} \mathrm{C}\right)\end{array}$ & $\begin{array}{l}\text { Time } \\
(\mathrm{min})\end{array}$ & $\begin{array}{l}\text { Positioning } \\
\text { Accuracy } \\
(\mu \mathrm{m})\end{array}$ & $\begin{array}{c}\text { Variation of } \\
\text { Positioning } \\
\text { Accuracy }(\mu \mathrm{m})\end{array}$ & $\begin{array}{c}\text { Variation Rate of } \\
\text { Positioning Accuracy } \\
\left(\mu \mathrm{m} /\left(\min \cdot{ }^{\circ} \mathrm{C}\right)\right)\end{array}$ \\
\hline \multirow[t]{2}{*}{1} & $\begin{array}{l}\text { Without temp. } \\
\quad \text { control } 0\end{array}$ & 22.7 & 0 & 18.30 & 0 & 0 \\
\hline & $\begin{array}{l}\text { Without temp. } \\
\text { control } 60\end{array}$ & 27.8 & 60 & 17.37 & -0.93 & -0.00304 \\
\hline \multirow{2}{*}{2} & Stable temp. 0 & 23.7 & 0 & 17.96 & 0 & 0 \\
\hline & Stable temp. 100 & 23.8 & 100 & 16.14 & -1.82 & -0.18200 \\
\hline \multirow{2}{*}{3} & Temp. rise 0 & 23.8 & 0 & 16.14 & 0 & 0 \\
\hline & Temp. rise 63 & 33.3 & 63 & 20.69 & 4.55 & 0.00760 \\
\hline \multirow{2}{*}{4} & Temp. decline 0 & 23.6 & 0 & 14.93 & 0 & 0 \\
\hline & Temp. decline 66 & 15.7 & 66 & 22.94 & 8.01 & 0.01536 \\
\hline
\end{tabular}

To investigate the variations in positioning accuracy for a periodically-moving machine in summertime and wintertime, an air conditioning system was designed to simulate the operational temperature distributions in the daytime in summer and in the nighttime in winter, respectively. Figure 6 illustrates the temperature distributions within the chamber in the daytime in summer and in the nighttime in winter, which were generated by the designed air conditioning system. In the case of summer daytime hours, the initial operational temperature was approximately $23.5^{\circ} \mathrm{C}$, which gradually rose with time. At time $=160 \mathrm{~min}$, the operational temperature reached a value of $31^{\circ} \mathrm{C}$. Afterward, the operational temperature gradually declined with time and gradually returned to the value of $23.5^{\circ} \mathrm{C}$ at time $=338 \mathrm{~min}$. However, in the case of winter nighttime hours, the initial operational temperature was approximately $23.7^{\circ} \mathrm{C}$ which gradually decreased with time. At time $=249 \mathrm{~min}$, the operational temperature was reduced to a value of $15.4^{\circ} \mathrm{C}$. Afterward, the operational temperature gradually rose with time. At time $=362 \mathrm{~min}$, the operational temperature gradually returned to the value of $22.5^{\circ} \mathrm{C}$.

Table 2 illustrates the corresponding positioning accuracies and corresponding variations of the moving carrier operating in summer daytime and winter nighttime hours. In the case of summer daytime conditions, the positioning accuracy slowly reduced with time as the operational temperature initially rose. However, as the operational temperature gradually declined to the value of $23.5^{\circ} \mathrm{C}$ from $31.8^{\circ} \mathrm{C}$, the positioning accuracy significantly worsened from 11.33 to $15.74 \mu \mathrm{m}$ with a variation of $4.41 \mu \mathrm{m}$ and a variation rate of $0.00425 \mu \mathrm{m} /\left(\mathrm{min} \cdot{ }^{\circ} \mathrm{C}\right)$. For summer daytime conditions, we found that a decline in the operational temperature (from 31.8 to $23.3^{\circ} \mathrm{C}$ ) caused the positioning accuracy to worsen for a periodically-moving carrier. In the case of winter nighttime conditions, while the operational temperature gradually declined from 23.7 to $15.4^{\circ} \mathrm{C}$, the positioning accuracy significantly worsened from 10.45 to $24.06 \mu \mathrm{m}$ with a considerable variation of $13.61 \mu \mathrm{m}$ and a variation rate of 
$0.00858 \mu \mathrm{m} /\left(\min \cdot{ }^{\circ} \mathrm{C}\right)$. Afterward, as the operational temperature returned to $22.7^{\circ} \mathrm{C}$, the positioning accuracy still slowly worsened to a value of $26.61 \mu \mathrm{m}$ once more. In the two cases, we found that a decline in the operational temperature (from 23.7 to $15.4^{\circ} \mathrm{C}$ ) causes the positioning accuracy to worsen greatly for a periodically-moving carrier in comparison to the effect of an operational temperature rise.

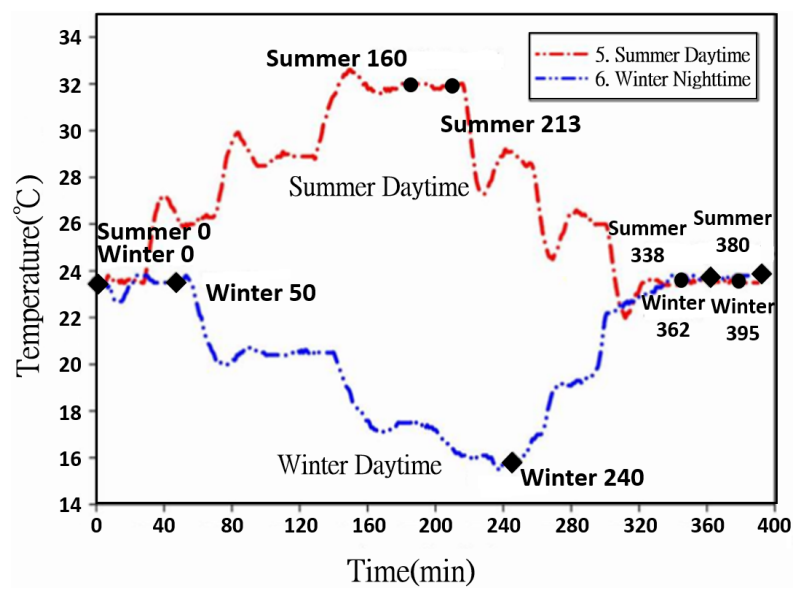

Figure 6. Temperature distributions within the environmental chamber according to time under summer daytime and winter nighttime operational conditions.

The heat sources of a moving carrier come from the friction of the moving carrier and the driving linear motor. In the case of an environmental temperature decline, the temperature differences between the environment and the heat sources are larger than those in the case of an environmental temperature rise. The larger temperature differences in the case of an environmental temperature decline cause greater positioning accuracy variations. This is the reason why the positioning accuracies for an environmental temperature decline are greater than for environmental temperature increases, as shown in Tables 1 and 2. In this study, each experiment was performed at least five times, and the uncertainties of the measured positioning accuracies and temperatures were $4.6 \%$ and $1.01 \%$, respectively.

Table 2. Corresponding positioning accuracies and corresponding variations of a periodically-moving carrier operating in the summer daytime and winter nighttime modes, respectively.

\begin{tabular}{|c|c|c|c|c|c|c|}
\hline No. & Time Point & $\begin{array}{c}\text { Chamber } \\
\text { Temperature } \\
\left({ }^{\circ} \mathrm{C}\right)\end{array}$ & $\begin{array}{l}\text { Time } \\
\text { (min) }\end{array}$ & $\begin{array}{l}\text { Positioning } \\
\text { Accuracy } \\
(\mu \mathrm{m})\end{array}$ & $\begin{array}{c}\text { Variation of } \\
\text { Positioning } \\
\text { Accuracy }(\mu \mathrm{m})\end{array}$ & $\begin{array}{l}\text { Variation Rate of } \\
\text { Positioning Accuracy } \\
\left(\mu \mathrm{m} /\left(\mathrm{min} \cdot{ }^{\circ} \mathrm{C}\right)\right)\end{array}$ \\
\hline \multirow{5}{*}{5} & Summer 0 & 23.5 & 0 & 12.42 & 0 & 0 \\
\hline & Summer 180 & 31.5 & 180 & 11.85 & -0.57 & -0.00040 \\
\hline & Summer 213 & 31.8 & 213 & 11.33 & -0.52 & -0.05253 \\
\hline & Summer 338 & 23.5 & 338 & 15.74 & 4.41 & 0.00425 \\
\hline & Summer 386 & 23.3 & 386 & 11.85 & -3.89 & -0.40521 \\
\hline \multirow{5}{*}{6} & Winter 0 & 23.7 & 0 & 13.42 & 0 & 0 \\
\hline & Winter 43 & 23.1 & 43 & 10.45 & -2.97 & -0.11512 \\
\hline & Winter 249 & 15.4 & 249 & 24.06 & 13.61 & 0.00858 \\
\hline & Winter 362 & 22.5 & 362 & 27.09 & 3.03 & 0.00378 \\
\hline & Winter 391 & 22.7 & 391 & 26.61 & -0.48 & -0.08276 \\
\hline
\end{tabular}

\subsection{Theoretical Models and Numerical Results of Flow and Temperature Fields}

In order to understand the effect of flow patterns on positioning accuracy within an environmental chamber, flow fields and temperature fields were simulated. To simplify the simulation, we assume that the air is in an environment containing low air velocity and is non-compressible, and the flow field is in an unsteady-state in terms of the computational domain. Navier-Stokes equations within the 
time average featuring the unsteady-state and three-dimensional non-compressible flow fields can be described as follows:

$$
\begin{gathered}
\frac{\partial U_{j}}{\partial x_{j}}=0, j=1,2,3 \\
\frac{\partial\left(U_{i} U_{j}\right)}{\partial x_{j}}=-\frac{1}{\rho} \frac{\partial P}{\partial x_{j}}-g_{i} \beta\left(T-T_{\infty}\right)+\frac{\partial}{\partial x_{j}}\left[v \frac{\partial U_{i}}{\partial x_{j}}-\overline{u_{i} u_{j}}\right] \\
\frac{\partial\left(T U_{j}\right)}{\partial x_{j}}=\frac{\partial}{\partial x_{j}}\left[\frac{v}{P_{r}} \frac{\partial T}{\partial x_{j}}-\overline{T^{\prime} u_{j}}\right]
\end{gathered}
$$

In the equations, $U_{j}, T$, and $P$ represent the average velocity, average temperature, and average pressure, respectively. The Boussinesq buoyancy effect was taken into consideration, and $\beta$ refers to the coefficient of thermal expansion. With a closed turbulence model, the turbulent stress $-\overline{u_{i} u_{j}}$ and turbulent thermal flux $-\overline{T^{\prime} u_{j}}$ can be obtained by the following expression:

$$
-\overline{u_{i} u_{j}}=2 v_{t} S_{i j}-\frac{2}{3} k \delta_{i j}-\overline{T^{\prime u_{j}}}=\frac{v_{t}}{P r_{t}}\left[\frac{\partial T}{\partial x_{j}}\right]
$$

In the expression, $v_{t}$ and $P r_{t}$ represent the turbulent flow viscosity and the turbulent Prandtl number, respectively. $K$ refers to the kinetic turbulent energy, while $k=\overline{u_{x}^{2}}+\overline{u_{y}^{2}}+\overline{u_{z}^{2}} / 3$ and $\delta_{i j}$ indicates the Kronecker delta. By solving the closed turbulence problem through the $k-\varepsilon$ model (kinetic turbulent energy equation and turbulent dissipation equation), the turbulent stress and thermal flux can be acquired. The commercial software, ANSYS Fluent (15.0, ANSYS. Inc, Cecil, PA, USA, 2014), was adopted in the simulation of the flow field and temperature field within the processing area.

In this study, the flow fields of the internal and external environments were filled with an ordinary air flow, with its physical parameters listed in Table 3 . The carrier and linear guideway components used in this study were made of cast iron and stainless steel, respectively, with their relevant physical parameters listed in Table 4 . The heat generating rates from the heat sources of the linear guideway and linear motor were 7575 and $1000 \mathrm{~W} / \mathrm{m}^{3}$, respectively, and were estimated from the simulation results and measurement data. To simulate the movement of the carrier on the guideway, dynamic grids were adopted in the numerical simulation.

Table 3. Air flow physical parameters.

\begin{tabular}{cc}
\hline Density & $\mathbf{1 . 1 8 2 4}\left(\mathbf{k g} / \mathrm{m}^{3}\right)$ \\
\hline Specific heat & $1005(\mathrm{~J} /(\mathrm{kg} \cdot \mathrm{K}))$ \\
Heat conductivity & $0.0261(\mathrm{~W} /(\mathrm{m} \cdot \mathrm{K}))$ \\
Viscosity & $1.834 \times 10^{-5}(\mathrm{~kg} /(\mathrm{m} \mathrm{s}))$ \\
Coefficient of heat transfer & $0.00326\left(\mathrm{~W} /\left(\mathrm{m}^{2} \cdot \mathrm{K}\right)\right)$ \\
Prandtl number & 0.708 \\
\hline
\end{tabular}

Table 4. Material parameters of stainless steel and cast iron.

\begin{tabular}{ccc}
\hline Physical Properties & Cast Iron & Stainless Steel \\
\hline Density $\left(\mathrm{kg} / \mathrm{m}^{3}\right)$ & 7850 & 7900 \\
Specific heat $(\mathrm{J} /(\mathrm{kg} \cdot \mathrm{K}))$ & 440 & 500 \\
Heat conductivity $(\mathrm{W} /(\mathrm{m} \cdot \mathrm{K}))$ & 46 & 16 \\
Thermal diffusivity $\left(\mathrm{m}^{2} / \mathrm{s}\right)$ & 0.0000133 & 0.0000041 \\
Thermal Expansion $(\mu \mathrm{m} /(\mathrm{m} \cdot \mathrm{K}))$ & 10.5 & 17 \\
\hline
\end{tabular}

From the above experimental results, it was found that an operational temperature variation may cause a great increase in positioning accuracy, especially in the operational condition of a temperature 
decline. To maintain a stable operational environment for a moving machine, the moving machine can be operated within an environmental chamber in which the temperature distributions can be controlled by an air conditioning system. Figure 7 illustrates the numerical average temperature distributions on a two-dimensional plane above the moving carrier along the moving path of the periodically-moving carrier. In Figure 7, each average value corresponding to the individual position above the moving carrier was calculated by averaging temperatures along the lateral direction ( $\mathrm{Z}$ axis) above the carrier during a moving period. From the average temperature distributions, the temperature deviations in the cases of different inlet/outlet vent locations can be presented. As shown in the figure, the air velocity at the inlets in cases $A, B, C$, and D was set to $2.36,1.18,2.36$, and $1.18 \mathrm{~m} / \mathrm{s}$, respectively. In order to maintain a stable and stratified flow field in the region near the moving machine, a laminar flow should be ensured in the corresponding region. For fluid dynamics in the internal flow, the non-dimensional parameter, the Reynolds number, should be below 2300. The definition of a Reynolds number is $\operatorname{Re}=\rho V D / \mu$, where $\rho$ in the density, $\mu$ is the viscosity of the fluid, $V$ is the characteristic velocity and $D$ is the characteristic dimension. In this study, the setting inlet velocities of 1.18 and $2.36 \mathrm{~m} / \mathrm{s}$ were adopted, and the characteristic velocities around the moving machine were about 0.08 and $0.12 \mathrm{~m} / \mathrm{s}$, respectively. The corresponding Reynolds numbers for both cases were 1289 and 1934, respectively, which are both less than the critical value of 2300 . When the air inlet and outlet were designed on the same side of the chamber (cases $C$ and $D$ ), the average temperature distributions above the moving carrier could be controlled at about $23^{\circ} \mathrm{C}$ with a maximum variation of $0.4{ }^{\circ} \mathrm{C}$. However, in cases A and B, in which the air inlets and outlets were located on opposite sides of the walls, it was found that the average temperature distributions along the moving path of the carrier were maintained within a deviation of $0.1^{\circ} \mathrm{C}$. In comparison to cases $\mathrm{C}$ and $\mathrm{D}$, the flow fields in cases $\mathrm{A}$ and $\mathrm{B}$ exhibited a smooth and parallel flow pattern. Thus, the temperature deviations in those two cases were much less than those in cases $C$ and D. Figure 8 shows the flow fields and temperature contours in the chamber in the cases where the air inlets and outlets were located, respectively, on opposite sides and on the same side at the inlet air velocity of $2.36 \mathrm{~m} / \mathrm{s}$. The flow field in the case where the air inlets and outlets were located on opposite sides exhibited a smooth and parallel flow pattern, and the heat can be effectively dissipated by flow convection in this case. Conversely, a large flow circulation was formed in the chamber in the case where the air inlets and outlets were located at the same wall, which may hinder the heat to dissipate from the air outlet, as shown in the figure. Thus, the temperature distributions on the linear guideway are higher than the case where the air inlets and outlets were located on opposite sides.

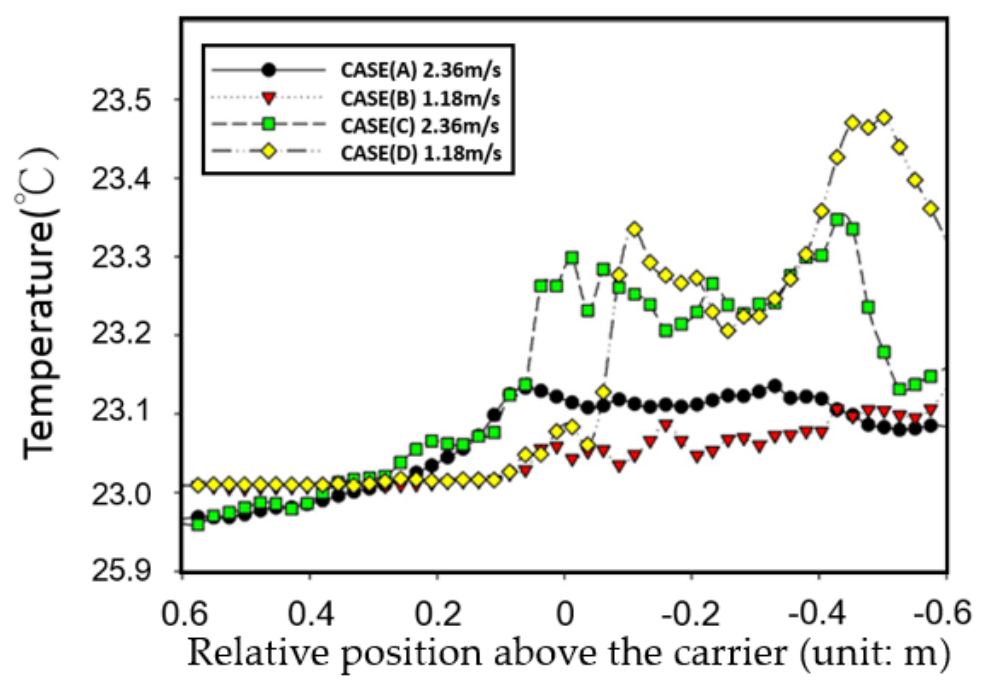

Figure 7. Numerical average temperature distributions along the moving path of a periodic moving carrier. 

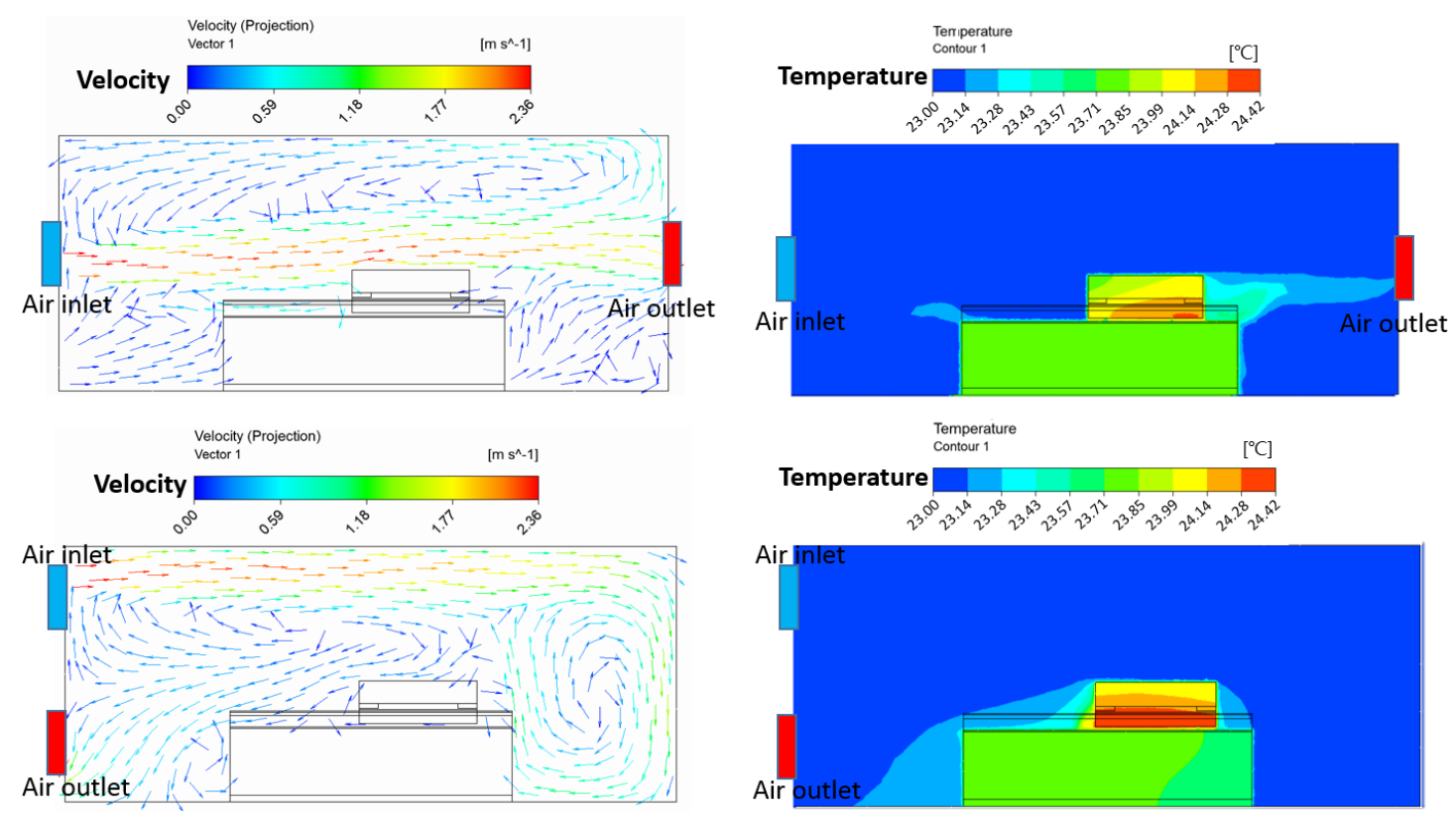

Figure 8. The flow fields and temperature contours in the chamber in the cases where the air inlets and outlets were located, respectively, on opposite sides and on the same side at the inlet air velocity of $2.36 \mathrm{~m} / \mathrm{s}$.

In addition, in this study, under the same feeding speed for a moving carrier, the positioning precision of the moving carrier varied with respect to the ambient temperature. From the dimensions of a single axial moving carrier, as shown in Figure 1, and the thermal expansion coefficients of the cast iron and stainless steel materials, as shown in Table 4, the positioning precision variation at $23.8^{\circ} \mathrm{C}$ was estimated to be $22.8 \mu \mathrm{m}$. In comparison to the experimental positioning precision variation at $23.8^{\circ} \mathrm{C}$, as shown at stable temp. 100 in Table 1, the estimated value is approximately $6.6 \mu \mathrm{m}$ larger than the experimental value. This is because the estimated value is calculated under a thermal steady-state condition. In the experiment, although the temperature was maintained for $100 \mathrm{~min}$, the structural temperature of the moving carrier was still in a transitional state instead of a steady state. From the viewpoint of thermal diffusivity, the thermal diffusivity of cast iron is less than that of stainless steel, and the heat conduction speed in cast iron will be slower in the structure of a moving carrier. Thus, more time is required for the machine to reach a thermal steady-state condition in the experiment.

In the cases in which the air inlet and outlet are located on opposite sides of the walls, the deviation distributions of the average temperature along the moving path of the carrier can be maintained in $0.1{ }^{\circ} \mathrm{C}$ due to parallel and stratified flow distributions. The positioning accuracy of $14.21 \mu \mathrm{m}$ for the carrier was experimentally measured in this case. The positioning accuracy's experimental value is less than the positioning accuracy's measured value of $16.14 \mu \mathrm{m}$, as shown for the stable temp. $100 \mathrm{in}$ Table 1, in the case in which the air inlet and outlet are located on the same side of the chamber. Thus, the air inlet and outlet locations on opposite sides of the walls are recommended in this study.

\section{Conclusions}

This study investigated the effect of the ambient environmental temperature on the positioning accuracy of a periodically-moving carrier. The moving carrier was operated in an environmental chamber in which the operational temperature could be controlled by an air conditioning system. Different operational temperature modes, including a stable temperature, a temperature rise, a temperature decline, summer daytime hours, and winter nighttime hours, in terms of seasonal climate change in Taiwan, were generated within the environmental chamber by the air conditioning system to investigate the operational temperature's effect on positioning accuracy. From the experimental 
measurements of the periodically-moving carrier, it is found that the operational temperature conditions can significantly affect the positioning accuracy of the moving carrier, especially in the case of an operational temperature decline. Under stable operational conditions, the positioning accuracy of a moving carrier can be considerably improved. In comparison to the case of an operational temperature decline, the positioning accuracy improvement reached $29.6 \%$.

Thus, under a stable operational temperature, the positioning accuracy of a moving carrier can be significantly improved. Moreover, the temperature distributions within the chamber were numerically investigated, showing that with a parallel flow pattern in the chamber, the movement of the carrier can cause less of a temperature variation in the chamber. The positioning accuracy can be further enhanced by a parallel flow pattern design. In the study, the ventilation design can be applied to the designs of semiconductor equipment, and electronic, optical, and measuring components in which effective heat dissipations are necessary.

In this study, the positioning accuracy analysis for a single-axial carrier was investigated experimentally. The results obtained in this study can become a useful reference for the design of one-dimensional moving machines, such as a surface measuring system, hardness testing device, image measuring machine, and so on. Based on the results, the positioning accuracy in two-axial, three-axial, or even five-axial machines can be evaluated.

Acknowledgments: The author gratefully acknowledges the financial support provided to this study by the Industrial Technology Research Institute under grant no. NCUT15TEP001.

Author Contributions: Win-Jet Luo and Kun-Ying Li conceived and designed the experiments; Win-Jet Luo performed the experiments; Jun-Zheng Huang, Pratikto and Yung-Chao Chan analyzed the data; Win-Jet Luo and Kun-Ying Li contributed reagents/materials/analysis tools; and Kun-Ying Li, Pratikto and Dini Faridah wrote the paper.

Conflicts of Interest: The authors declare no conflict of interest.

\section{References}

1. Yang, Z.; Chen, C.; Chen, F.; Li, G. Progress in the research of reliability technology of machine tools. J. Mech. Eng. 2013, 49, 130-139. [CrossRef]

2. Lad, B.K.; Kulkarn, M.S. Reliability and maintenance based design of machine tools. Int. J. Perform. Eng. 2013, 9, 321-332.

3. Zhang, Y.; Zheng, R.; Shen, G.; Chen, B. Reliability analysis for CNC machine tool based on failure interaction. Commun. Comput. Inf. Sci. 2011, 134, 489-496.

4. Loganathan, M.K.; Gandhi, O.P. Reliability evaluation and analysis of CNC cam shaft grinding machine. J. Eng. Des. Technol. 2015, 13, 37-73. [CrossRef]

5. Merrick, J.R.W.; Soyer, R.; Mazzuchi, T.A. A bayesian semiparametric analysis of the reliability and maintenance of machine tools. Technometrics 2003, 45, 58-69. [CrossRef]

6. Ramesh, R.; Mannan, M.A.; Poo, A.N. Error compensation in machine tools-A review: Part II: Thermal errors. Int. J. Mach. Tools Manuf. 2000, 40, 1257-1284. [CrossRef]

7. Mayr, J.; Jedrzejewski, J.; Uhlmann, E.; Alkan, D.M. Thermal issues in machine tools. CIRP Ann.—Manuf. Technol. 2012, 61, 771-791. [CrossRef]

8. Ramesh, R.; Mannan, M.A.; Poo, A.N. Thermal error measurement and modeling in machine tools: Part I. Influence of varying operating conditions. Int. J. Mach. Tools Manuf. 2003, 43, 391-404. [CrossRef]

9. Jenq-Shyong, C.; Wei-Yao, H. Characterizations and models for the thermal growth of a motorized high speed spindle. Int. J. Mach. Tools Manuf. 2003, 43, 1163-1170.

10. Sun-Kyu, L.; Jae-Heung, Y.; Moon-Su, Y. Effect of thermal deformation on machine tool slide guide motion. Tribol. Int. 2003, 36, 41-47.

11. Xia, J.; $\mathrm{Wu}, \mathrm{B} . ; \mathrm{Hu}, \mathrm{Y}$.; Shi, T. Experimental research on factors influencing thermal dynamics characteristics of feed system. Precis. Eng. 2010, 34, 357-368.

12. Mian, N.S.; Fletcher, S.; Longstaff, A.P.; Myers, A. Efficient estimation by FEA of machine tool distortion due to environmental temperature perturbations. Precis. Eng. 2013, 37, 372-379. [CrossRef] 
13. Tan, B.; Mao, X.; Liu, H.; Li, B.; He, S.; Peng, F.; Ling, Y. A thermal error model for large machine tools that considers environmental thermal hysteresis effects. Int. J. Mach. Tools Manuf. 2014, 82-83, 11-20.

14. Wang, W.; Kececioglu, D.B. Fitting the Weibull log linear model to accelerated life-test data. IEEE Trans. Reliab. 2000, 49, 217-223. [CrossRef]

15. Toshimichi, M.; Chenghe, Z.; Motonobu, N. Thermal deformation of machining center due to temperature change in the environment. Trans. Jpn. Soc. Mech. Eng. Ser. C 1991, 539, 2447-2452.

16. Toshimichi, M.; Eiji, S. Analysis of thermal deformation of an ultra precision air spindle system. CIRP Ann.-Manuf. Tech. 1998, 47, 315-319.

17. Fletcher, S.; Longstaff, A.P.; Myers, A. Flexible modeling and compensation of machine tool thermal errors. In Proceedings of the 20th Annual Meeting of American Society for Precision Engineering, Norfolk, VA, USA, 9-14 October 2005.

18. Diaz-Elsayed, N.; Dornfeld, D.; Horvath, A. A comparative analysis of the environmental impacts of machine tool manufacturing facilities. J. Clean. Prod. 2015, 95, 223-231. [CrossRef]

19. Diaz, N.; Helu, M.; Jayanathan, S.; Horvath, A.; Dornfeld, D. Environmental analysis of milling machine tool use in various manufacturing environments. In Proceedings of the 2010 IEEE International Symposium on Sustainable Systems and Technology (ISSST), Arlington, VA, USA, 17-19 May 2010; pp. 1-6.

20. Jin, S.M.; Shi, M. A Study of the Airflow Field and Temperature Field in an Artificial Environmental Laboratory. Master's Thesis, Nanjing Tech University, Nanjing, China, 2006.

21. Li, Y.B.; Chou, W.; Lee, P.F.; Wang, X.C. Temperature homogeneity control of greenhouse based on CFD simulation model. Trans. Chin. Soc. Agric. Mach. 2012, 43, 156-161.

22. Chang, H. A Study of the Control Mechanism and System of Micro-Nano Measurement Environment. Ph.D. Thesis, Hefei University of Technology, Heifei, China, 2009.

23. Kashiwa: Precise vs. Insufficient Explanation. Available online: http://www.ic.u-tokyo.ac.jp/kashiwa/ english/tips/tip17.html (accessed on 13 October 2016).

24. Renishaw: Interferometry Explained. Available online: http://www.renishaw.com/en/interferometryexplained--7854 (accessed on 13 October 2016).

(C) 2017 by the authors. Licensee MDPI, Basel, Switzerland. This article is an open access article distributed under the terms and conditions of the Creative Commons Attribution (CC BY) license (http:/ / creativecommons.org/licenses/by/4.0/). 